\title{
Experimental and computational studies on activated Bambara groundnut (Vigna subterranean) hulls for the adsorptive removal of herbicides from aqueous solution
}

\author{
Thomas Aondofa Nyijime ${ }^{1,1^{*}}$ (D, Abdullahi Muhammad Ayuba ${ }^{1,1^{*}}$ and Habibat Faith Chahul ${ }^{2}$
}

\begin{abstract}
Background: The excessive usage of herbicides to control herbs by farmers has become an issue of interest to the environmentalist due to the threat posed by such act to the ecosystem, and therefore, there is the need to curb such practices. The efficiency of Bambara groundnut shell for the removal of pendimethalin (PE) and paraquat dichloride $(\mathrm{PQ})$ herbicides from aqueous solution was established in this work. The activated carbon was prepared via chemical activation method using trioxonitrate $(v)$ acid by determining its void volume, moisture content, bulk density and Fourier transform infrared (FTIR) and scanning electron microscopy (SEM) methods. Batch adsorption techniques were set to optimize the adsorption parameters such as solution $\mathrm{pH}$, adsorbate concentration, contact time, adsorbent dosage and temperature in order to depict the best optimal conditions for the adsorption process. The adsorption process was examined in terms of its equilibrium data, kinetics, thermodynamics involved in the adsorption process as well as computational quantum chemical parameters evaluation.

Results: The batch adsorption experiments revealed that the amounts of PE and PQ adsorbed were found to vary with the contact time, adsorbent dosage, $\mathrm{pH}$ and initial concentration. The adsorption of PE and PQ decreased with increasing adsorbent dose but increases with increasing initial concentration of the PE and PQ solution. Isotherm studies revealed that the equilibrium data fitted to both Langmuir and Freundlich model with $R$-squared values of $0.976,0.993$ and $0.909,0.978$ for $P E$ and $P Q$, respectively, which implied that Langmuir isotherm had a better fit. This was also found to be an indication that the uptake of PE and PQ by ACBGNS occurred through monolayer adsorption on identical homogenous sites. Also, kinetic modeling results obtained showed that the pseudo-second-order model explained the adsorption kinetics of PE and PQ by ACBGNS best, which meant that chemisorption was the slowest step and, thus, the rate determining step. The positive value of $\triangle H$ and the positive value of $\triangle G$ show the endothermic and spontaneous nature of adsorption of PE and PQ ACBGNS.

Conclusion: Batch adsorption experiment and characterization of the ACBGNS have indicated that Bambara ground nut shell can be used to produce activated carbon that can be applied effectively for adsorption of PE and PQ from an aqueous solution. Computational studies results obtained from quantum chemical analysis are consistent with the experimental results obtained from this study.
\end{abstract}

Keywords: Adsorption, Bambara groundnut shell, Isotherm, Thermodynamic, Computational

\footnotetext{
*Correspondence: thomasnyijime@gmail.com

${ }^{1}$ Department of Pure and Industrial Chemistry, Bayero University, Kano,

Kano, Nigeria

Full list of author information is available at the end of the article
}

(c) The Author(s) 2021. Open Access This article is licensed under a Creative Commons Attribution 4.0 International License, which permits use, sharing, adaptation, distribution and reproduction in any medium or format, as long as you give appropriate credit to the original author(s) and the source, provide a link to the Creative Commons licence, and indicate if changes were made. The images or other third party material in this article are included in the article's Creative Commons licence, unless indicated otherwise in a credit line to the material. If material is not included in the article's Creative Commons licence and your intended use is not permitted by statutory regulation or exceeds the permitted use, you will need to obtain permission directly from the copyright holder. To view a copy of this licence, visit http://creativecommons.org/licenses/by/4.0/. 


\section{Background}

Farmers in developing countries like Nigeria are faced with various threats posed by unregulated and excessive usage of herbicides during farming processes which results in serious contamination and pollution of surface and ground waters (Neera 2009). These acts call for serious concern by environmentalists and their likes to curb such practices of the reckless use of these chemicals in crop farms, orchards, fields and forest lands (Neera 2009; Salman et al. 2011). Scientists have used several methods to control the unguided usage of these chemicals before, during and after farm practices of which adsorption finds an application. However, activated carbon usage in waste water treatments has been established to be more effective and efficient when compared to other adsorbent materials. This is due to its ease in experimental design and usage even though activated carbons which are commercially available are quite expensive (Ali et al. 2016; El-Shamy et al. 2018; Yanyan et al. 2018; Wei et al. 2019; Khan 2020; Alzhan et al. 2020; Liliana et al. 2020; Ahmed et al. 2020; Ahmed and Sayed 2020; Abdelhamid et al. 2020; Khalil and Kenawy 2020; El-Azazy et al. 2021). Reported studies on the use of Bambara groundnut shell do not involve using it to remove herbicides from an aqueous solution which could have led to understanding of the mechanism of the process (Ademola et al. 2019).

Pendimethalin was known as (3,4-dimethyl-2,6-dinitro-N-pentan-3-ylaniline) and that of paraquat dichloride (1,1-dimethyl-4,4-bipyridinium chloride). Pendimethalin and paraquat dichloride for their interaction with adsorbent surface. However, there is paucity in the usage of activated carbon sourced from Bambara groundnut shells (BGNS) for the adsorption of pendimethalin and paraquat dichloride. Bambara groundnut is an edible fruit that is cultivated mainly because of its high nutritional value. In northern Nigeria, large quantities of Bambara groundnut hulls are usually disposed as waste materials (Akinola et al. 2019). BGNS can be easily transformed and utilized as a good adsorbent. Most of the reported work on the use of BGNS product has to do with the ability of these adsorbents in adsorbing dyes (Akinola et al. 2019). There are few reports on the specific mode of action of the adsorbent and the extent of its adsorption (Akinola et al. 2019; Ayuba and Nyijime 2020).

In describing reactivity and illustrating chemical, molecular and electronic structure of compounds, quantum chemical methods have been found to find a lot of application (Kraka and Cremer 2000). This can assess the potentials and efficacy of the interaction between the adsorbent and adsorbate through mathematical intuitions and modeling. The correlation between structure and reactivity could be used to even predict the efficiency of compounds in adsorption which are yet to be synthesized (Kareison and Lebanov 1996). The use of equations of mathematical origin and models could be used to establish and predict chemical phenomena of which adsorption is such an example (Hinchliffe 1994, 1999). In this previous study, it was shown that the activated Bambara groundnut shell is established to be an efficient adsorbent which can be applied for the adsorption of both pendimethalin and paraquat dichloride herbicides form aqueous solution. It functions through surface adsorption sites which depend on experimental parameters including solution $\mathrm{pH}$, amount of adsorbent, time of contact and initial concentration of the herbicide. Physical process favors the adsorption of both PE and PQ herbicides on Bambara groundnut shell. Relatively based on the experimental data generated, the isotherm that fitted best was that of Langmuir model. The kinetics that best describes the adsorption process of both herbicides to the ACBGNS was that of second order (pseudo). Evaluated parameters obtained for both adsorption processes ( $\Delta G, \Delta H$ and $\Delta S$ ) describe the process to be spontaneous and feasible in nature.

Furthermore, this approach can harness the structural and electronic parameters of these molecules in relation to adsorption to propose a suitable mechanism which may not be achieved experimentally (Growcock 1989; Wang et al. 1999). The aim of the present study was to investigate and established the adsorption efficiency of activated Bambara groundnut shell in the removal of pendimethalin $(\mathrm{PE})$ and paraquat dichloride $(\mathrm{PQ})$ herbicides from aqueous solution.

\section{Methods}

\section{Chemicals and reagent}

Adsorbate tested pendimethalin (PE) and paraquat dichloride (PQ) herbicide were obtained from Yankura market, Kano, Nigeria. Pendimethalin [CAS number $=40487-42-1, \quad$ chemical formula $=\mathrm{C}_{13} \mathrm{~N}_{19} \mathrm{~N}_{3} \mathrm{O}_{4}$, molecular weight $\left.=281.312 \mathrm{~g} \mathrm{~mol}^{-1}\right]$ and paraquat dichloride [CAS number $=1910-42-5$, chemical formula $=\mathrm{C}_{12} \mathrm{H}_{14} \mathrm{Cl}_{2} \mathrm{~N}_{2}$, molecular weight $=257.16 \mathrm{~g} \mathrm{~mol}^{-1}$. Bambara groundnut shells (BGNS) were collected as a waste material from some farms in Benue, Nigeria. The collected BGNS were washed with distilled water to eliminate any dirt. All chemicals used were of the analytical grade. Sodium hydroxide, phosphoric acid, hydrochloric acid were the products of Sigma-Aldrich (Darmstadt, Germany).

\section{Preparation of adsorbent}

The BGNS sourced after removing the seeds from the pods were thoroughly washed to clear off impurities using water. Shells obtained were subjected to drying at $80^{\circ} \mathrm{C}$ to obtain constant weight. Pulverization and 
subsequent sieving of the dried shells into fine particles were conducted as described by Ayuba and Nyijime (2021). The final product was kept for further usage in an air safe container. $100 \mathrm{~g}$ of the fine powder was mixed with $10 \%$ phosphoric acid $\left(\mathrm{H}_{3} \mathrm{PO}_{4}\right)(100 \mathrm{~g}$ sample $+100 \mathrm{mg} / \mathrm{l}$ of $10 \% \mathrm{H}_{3} \mathrm{PO}_{4}$, wt/v). Pyrolysis in an electric muffle furnace of the fine particles was conducted for $1 \mathrm{~h}$ at $450{ }^{\circ} \mathrm{C}$ and subsequently removed and cooled at room temperature. Before drying at $110{ }^{\circ} \mathrm{C}$ at a period of $24 \mathrm{~h}$, the pyrolyzed carbon was subjected to washing using $2 \% \mathrm{HCl}$ and distilled water to achieve a neutral $\mathrm{pH}$ sample (Ayuba and Nyijime 2021).

\section{Preparation of herbicides solutions}

The stock herbicides solution was prepared by mixing $3.6 \mathrm{ml}$ of the $276 \mathrm{mg} / \mathrm{l}$ of PQ solution and $2 \mathrm{ml}$ of $500 \mathrm{mg} / \mathrm{l}$ of PE solution separately each to a 1-L flask and further diluting to the mark. Serial dilution was carried out using distilled water to give solution concentration of $10,20,30,40,50$ and $60 \mathrm{mg} / \mathrm{l}$ of each herbicides solution.

\section{Batch adsorption experiments}

Adsorption experiments for PE or PQ onto the prepared adsorbent were studied by weighing $0.1 \mathrm{~g}$ of the adsorbent (ACBGNS), and $10 \mathrm{~cm}^{3}$ of $50 \mathrm{ml}$ initial concentration (PQ or PE) was introduced into a $250-\mathrm{ml}$ beaker and was tightly covered and placed in an incubator shaker (Innova model) and run at $25{ }^{\circ} \mathrm{C}$ for $2 \mathrm{~h}$. After equilibration, samples were withdrawn and filtered through Whatmann filter paper and the absorbance of the residual herbicides was measured using a Uv-visible spectrophotometer (PerkinElemer) at $\lambda_{\max } 243$ and $257 \mathrm{~nm}$ for pendimethalin and paraquat dichloride, respectively. The same method was used while varying the initial concentration, the contact time, the adsorbent dosage and temperature of adsorption during optimization experiments. The optimized values were used to conduct the main batch adsorption experiments at varying temperatures $(60 \mathrm{mg} / \mathrm{l}$ concentration, $0.2 \mathrm{~g}$ dosage, $\mathrm{pH} 6$ and $\mathrm{pH}$ 8,80 min contact time for $\mathrm{PE}$ and $\mathrm{PQ}$, respectively). The amount of the herbicide adsorbed for each gram was obtained using Eq. (1) (Fouodouo et al. 2017).

$$
\text { Herbicide uptake, } q_{\mathrm{e}}=\frac{\left(C_{\mathrm{o}}-C_{\mathrm{e}}\right) V}{m}
$$

The initial and equilibrium concentration $(\mathrm{mg} / \mathrm{l})$ are defined as $C_{\mathrm{o}}$ and $C_{\mathrm{e}}$, volume of the herbicide solution $(L)$ is $V$, and the mass $(g)$ of ACBGNS is $m$.

\section{Characterization of the adsorbent}

The adsorbent (ACBGNS) was characterized using Cary 630, Agilent Technology model of Fourier Transform Infrared Spectrophotometer and Scanning
Electron Microscope (Phenom World Eindhoven). The conducted FTIR experiment used a range of wave numbers $\left(650-4000 \mathrm{~cm}^{-1}\right)$ with 32 scans at $8 \mathrm{~cm}^{-1}$ resolution, while the SEM analysis was performed by scanning the micrographs of ACBGNS before and after adsorption using $15.00 \mathrm{kV}$ voltage of acceleration with an $\times 500$ magnification.

\section{Computational details}

All the geometries of the molecules have been fully optimized using the B3LYP method within the framework of density functional theory (DFT) housed in Materials Studio 7.0 software (Accelrys, Inc.) in conjunction with the double numerical polarization (DNP) basis set (Lee et al. 1988; Becke 1993). After obtaining the geometry optimized herbicide molecules, quantum chemical parameters were computed which were later used to predict the adsorption mechanisms (Tao et al. 2010; Mohammed et al. 2017; Zohdy et al. 2021). This method has been used to provide useful information about useful quantum chemical parameters (Khaled et al. 2005; Emreguland and Hayvali 2006; Zohdy et al. 2021), through density functional theory (DFT) to predict the structural nature of the adsorbate and adsorbent interaction processes (Lashkari and Arshadi 2004; Mohan and Joseph 2018). The electron affinity (EA) and ionization potential (IP) of the neutral herbicide molecules were calculated in relation to the lowest energy of the unoccupied molecular orbital $\left(E_{\mathrm{LUMO}}\right)$ and the highest occupied molecular orbital energy $\left(E_{\mathrm{HOMO}}\right)$, respectively, using Koopman's theory (1993).

$$
\begin{aligned}
& \mathrm{IP}=-E_{\text {HOMO }} \\
& \mathrm{EA}=-E_{\mathrm{LUMO}}
\end{aligned}
$$

Energy gas $\Delta E$ was calculated using Eq. (4):

$$
\Delta E=E_{\mathrm{LUMO}}-E_{\mathrm{HOMO}}
$$

Calculated ionization potential and electron affinity values were used to determine the values of the absolute electronegativity $\chi$, the absolute hardness $(\eta)$ and the softness $(\sigma)$ using expressions in Eqs. (5) and (6): (Pearson 1963).

$$
\begin{aligned}
& \chi=\frac{1}{2}(\mathrm{IP}+\mathrm{EA})=\frac{1}{2}\left(-E_{\mathrm{HOMO}}-E_{\mathrm{LUMO}}\right) \\
& \eta=\frac{1}{2}(\mathrm{IP}-\mathrm{EA})=\frac{1}{2}\left(E_{\mathrm{LUMO}}-E_{\mathrm{HOMO}}\right)
\end{aligned}
$$

Value of the global softness $(\sigma)$ is the reciprocal of the global hardness (Pearson 1963). 


$$
\sigma=1 / \eta
$$

For a reaction made of adsorbent and adsorbate having varying electro negativities, the flow of electrons is expected from the adsorbate molecule having lower electronegativity toward that with a higher negativity (adsorbent surface) till equilibrium of the chemical potentials of both systems is attained (Parr and Szentpaly 1999).

Fukui indices were used to establish the reactive sites on the herbicide (adsorbate) which shows chemically reactive regions of the electrophilic and nucleophilic character of the studied herbicide molecules (Verma et al. 2018). Chemically, where the function of the Fukui is found to have large values predicts a region of higher reactivity than where the value is small. To further predict the sites which can serve as hard and soft acid and bases, the HSAB principle can be invoked in relation to the evaluated Fukui indices. To define Fukui function $f(r)$ for nucleophilic attack (Eq. 8) and electrophilic attack (Eq. 9) depending on the direction of electron transfer, the scheme of finite difference approximations obtained from Mulliken population analysis of atoms in the herbicide molecules was used (Alibakhshi et al. 2018; Verma et al. 2018; Zohdy et al. 2021).

$$
\begin{aligned}
& f_{k}^{+}=q_{k(N+1)-} q_{k(N)} \\
& f_{k}^{-}=q_{k(N)-} q_{k(N-1)}
\end{aligned}
$$

Value of $q_{k}$ is the molecule's gross atom charge, the number of electrons $(N)$ in the molecule, the anion is $N+1$ describing the LUMO of the neutral molecule with an added electron, and the cation is defined with respect to $N-1$ showing a new $\mathrm{HOMO}$ after electron removal from the neutral molecule. The ground state geometry of the herbicide molecules resulting from local minima was used for all calculations.

\section{Results}

The spectroscopic and micrograph results of this study are reported in Figs. 1 and 2, respectively. The optimized adsorption density of various adsorption parameters including solution $\mathrm{pH}$, contact time, adsorbent dosage, initial herbicide concentration is reported in Figs. 3, 4, 5 and 6. The calculated adsorption isotherm, kinetics study, thermodynamic as well as the calculated quantum chemical parameters and Fukui indices of pendimethalin and paraquat dichloride molecule are reported in Tables 1, 2, 3, 4 and 5, respectively. Figure 7 shows the optimized geometry, HOMO, LUMO of PE and PQ molecules.

\section{Discussion}

\section{Spectroscopic characterization of the adsorbent}

FT-IR spectra of pendimethalin and paraquat dichloride (Fig. $1 \mathrm{a}-\mathrm{c}$ ) before and after adsorption show five important peaks which include $\mathrm{O}-\mathrm{H}$ broad peak at $3117 \mathrm{~cm}^{-1}$. $\mathrm{C} \equiv \mathrm{C}$ vibration at $2322 \mathrm{~cm}^{-1}, 2084 \mathrm{~cm}^{-1}$ and $2113 \mathrm{~cm}^{-1}$, peaks at $1994 \mathrm{~cm}^{-1}$ and $1871 \mathrm{~cm}^{-1}$ which can be assigned to $\mathrm{C}=\mathrm{O}$ group; such assignments can be affected by neighboring aromatic $\mathrm{C}-\mathrm{C}$ ring stretched vibrations. At 1562 and $1063 \mathrm{~cm}^{-1}$, the following stretch assignments of $\mathrm{C}=\mathrm{C}$ and $\mathrm{C}-\mathrm{O}$ were observed The peaks at $970 \mathrm{~cm}^{-1}$, $873 \mathrm{~cm}^{-1}$ and $676 \mathrm{~cm}^{-1}$ correspond to $\mathrm{C}-\mathrm{H}$ in alkenes and $\mathrm{C}-\mathrm{H}$ in aromatic rings. There was a minor difference that was observed prior to and after adsorption, which resulted in a shift and broadening of adsorption peaks. The shift of the $-\mathrm{OH}$ peak from 3117 to $3339 \mathrm{~cm}^{-1}$ for pendimethalin and $3117 \mathrm{~cm}^{-1}$ to $3119 \mathrm{~cm}^{-1}$ for paraquat dichloride indicates the involvement of the hydroxyl groups in the adsorption of the herbicides (Abbas and Ahmed 2016; Jawad et al. 2018).

The micrograph of the surface of ACBGNS before adsorption (Fig. 2a) shows the morphology of the surface adsorbent having pores, cracks, holes which are expected to enhance adsorption. After adsorption of the two herbicides differently (Fig. 2b, c), the surfaces showed the formation of clusters, patches, with filled cracks on the ACBGNS surfaces which shows the participation of ACBGNS in the adsorption of PE and PQ.

Some of the obtained physical properties of the activated carbon produced 11.2 moisture content (\%), 0.242 density $\left(\mathrm{g} / \mathrm{cm}^{3}\right)$ and 1.78 pore volume $\left(\mathrm{cm}^{3}\right)$. The value of the moisture content pore volume and the bulk density of the produced activated carbon revealed that it had good adsorptive properties. It was noticed from the properties of the activated carbon that though it might not give up to $100 \%$ adsorption, it will be good for adsorption of organic and inorganic materials to a large extent (Fito et al. 2019). Maximum weight loss was observed in the present study; $51.82 \%$ of the activated carbon was obtained after activation.

\section{Effect of $\mathrm{pH}$ variation on $\mathrm{PE}$ and $\mathrm{PQ}$ adsorption}

Figure 3 shows the variation in $\mathrm{PE}$ and $\mathrm{PQ}$ amount adsorbed onto ACBGNS with solution pH. Removal of PE and PQ by ACBGNS is observed to be at optimum $\mathrm{pH}$ of 6 and 8. It can be observed from the plots that ACBGNS posses high removal of $\mathrm{PE}$ at lower $\mathrm{pH}$, while $\mathrm{PQ}$ was more adsorbed at higher $\mathrm{pH}$ condition. The presence of pectin on the surface of ACBGNS favored the adsorption of PQ which is cationic in nature; this is as a result of negatively charged ions increase in alkaline medium 


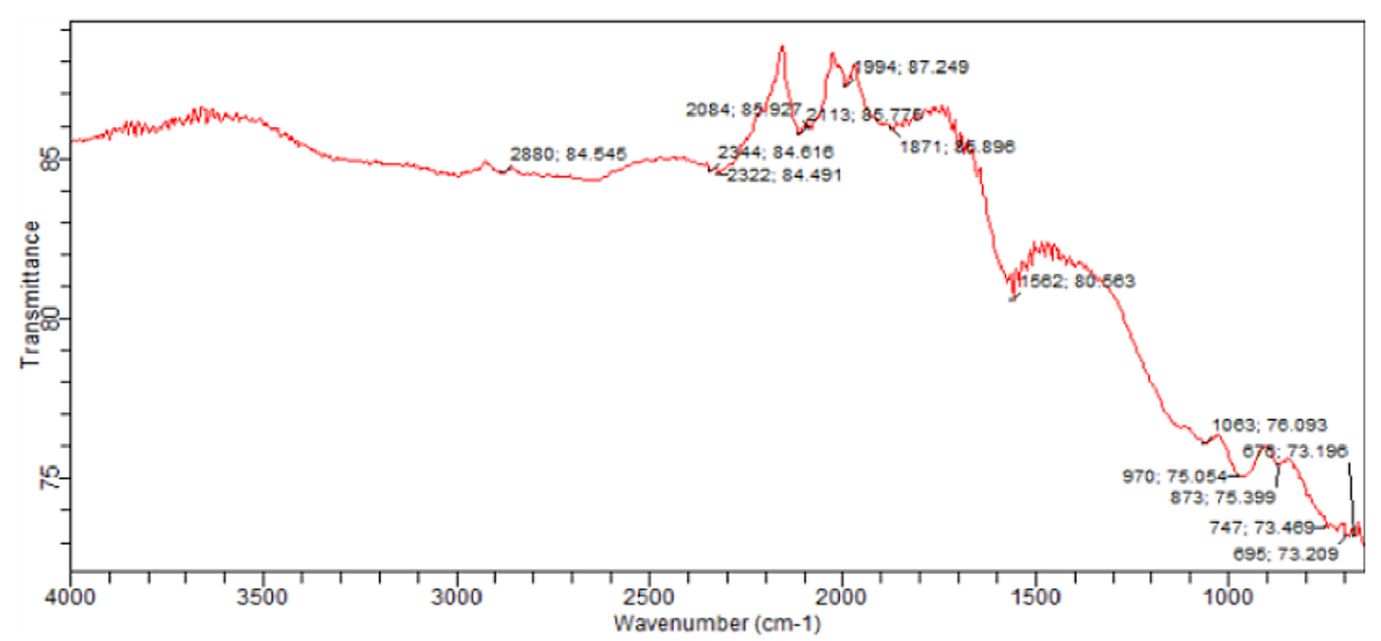

(a)

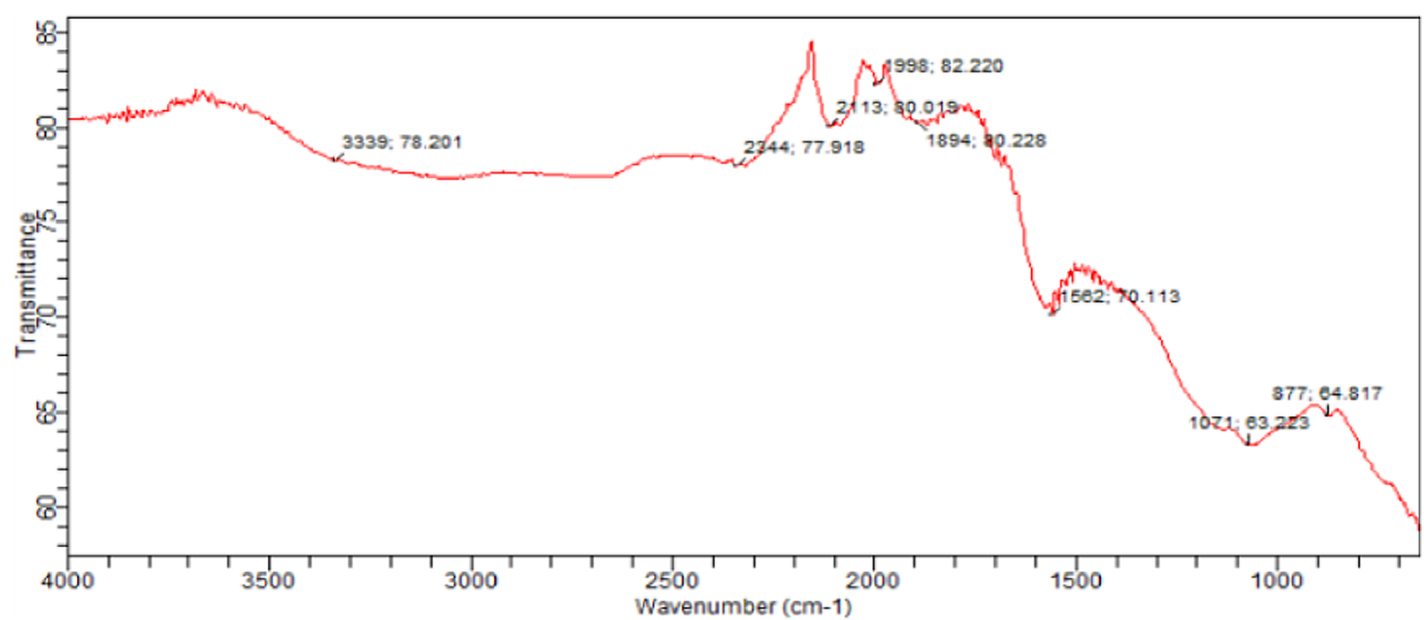

(b)

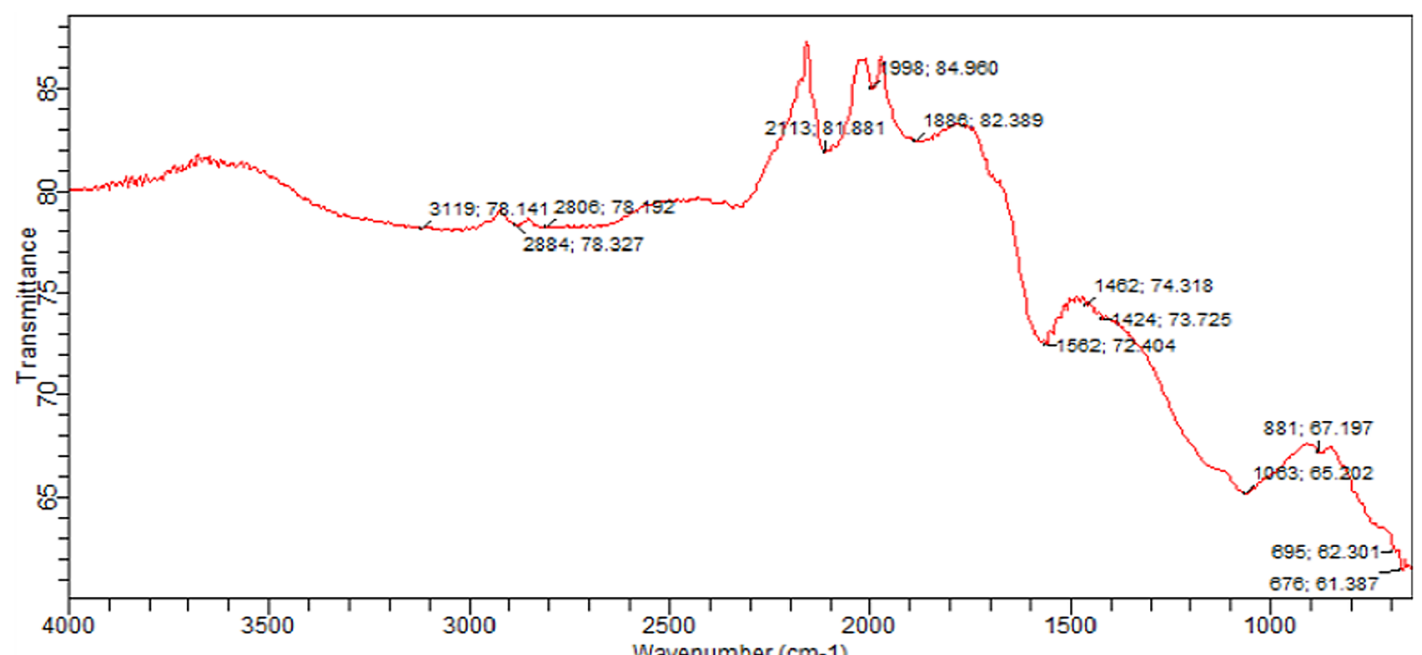

(c)

Fig. 1 FT-IR spectra of ACBGNS (a) before adsorption, (b) and (c) after the PE and PQ adsorption. The adsorbent (ACBGNS) was characterized using Cary 630, Agilent Technology model of Fourier Transform Infrared Spectrophotometer. The conducted FTIR experiment used a range of wave numbers $\left(650-4000 \mathrm{~cm}^{-1}\right)$ with 32 scans at $8 \mathrm{~cm}^{-1}$ resolution 


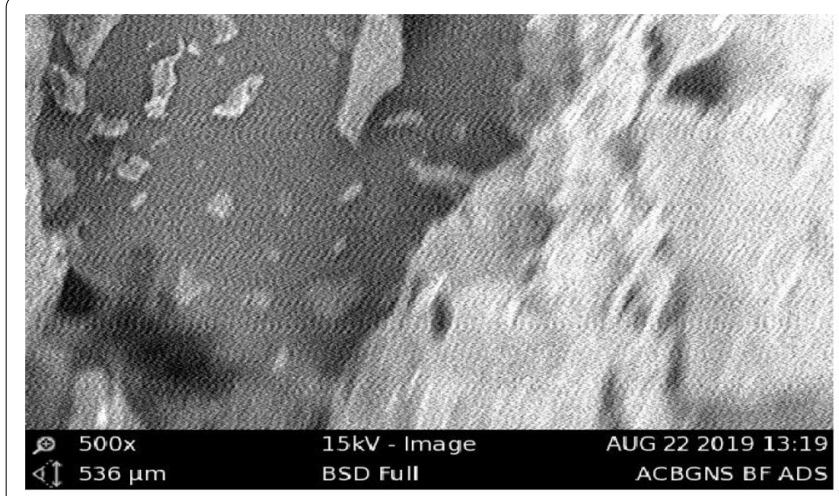

(a)

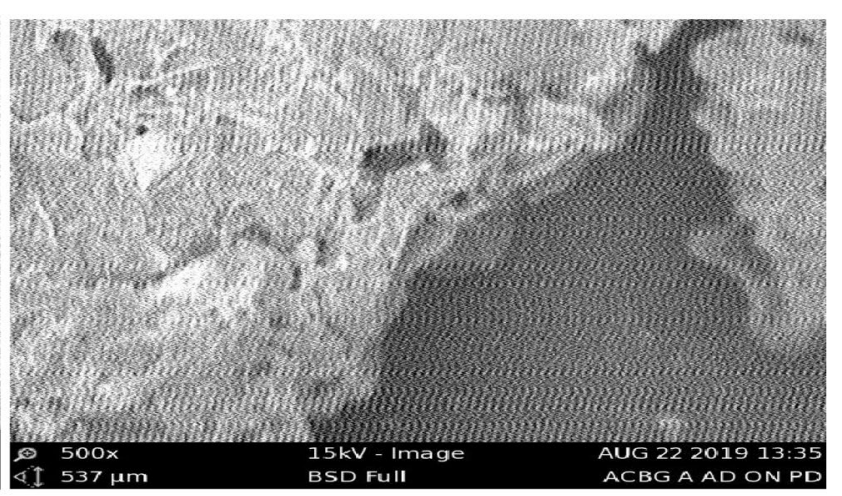

(b)

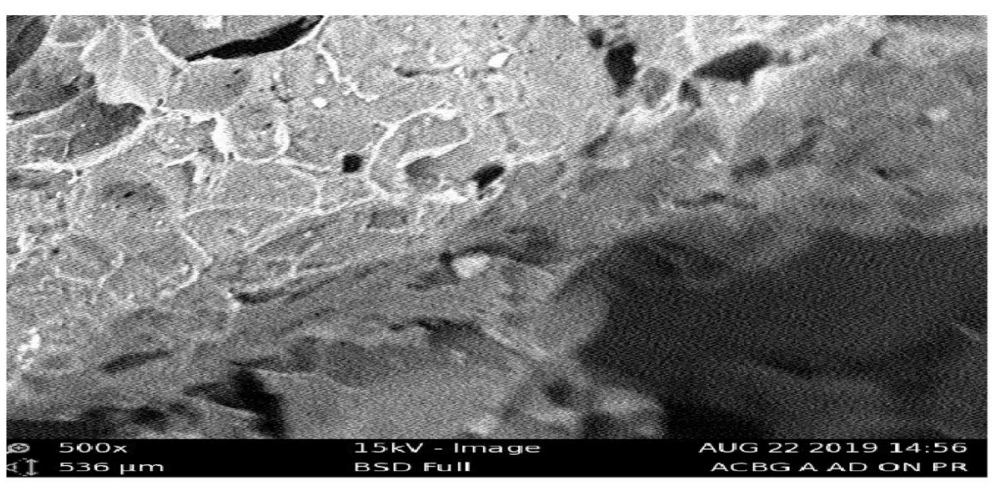

(c)

Fig. 2 SEM micrograph of ACBGNS (a) before adsorption and (b) after adsorption on PQ (c) after adsorption of PE. The adsorbent was characterized using scanning electron microscope (Phenom World Eindhoven). The SEM analysis was performed by scanning the micrographs of ACBGNS before and after adsorption using $15.00 \mathrm{kV}$ voltage of acceleration with an $\times 500$ magnification

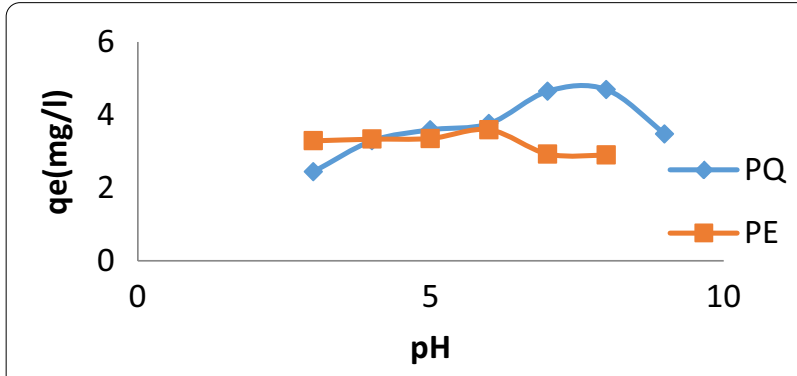

Fig. 3 Effect of $\mathrm{pH}$ on adsorption of PE and PQ (adsorption conditions: concentration of $\mathrm{PE}$ and $\mathrm{PQ}=50 \mathrm{mg} / \mathrm{l}, \mathrm{m}=0.1 \mathrm{~g}, t=24 \mathrm{~h}$, $T=25^{\circ} \mathrm{C}$, volume of solution $=10 \mathrm{~cm}^{3}$, agitation speed $=150 \mathrm{rmp}$ )

(Bello et al. 2017), while the surface of ACBGNS which also contains phenolic or carboxylic functional groups may be the reason for increased adsorption of PE at low pH (Bedin et al. 2015).

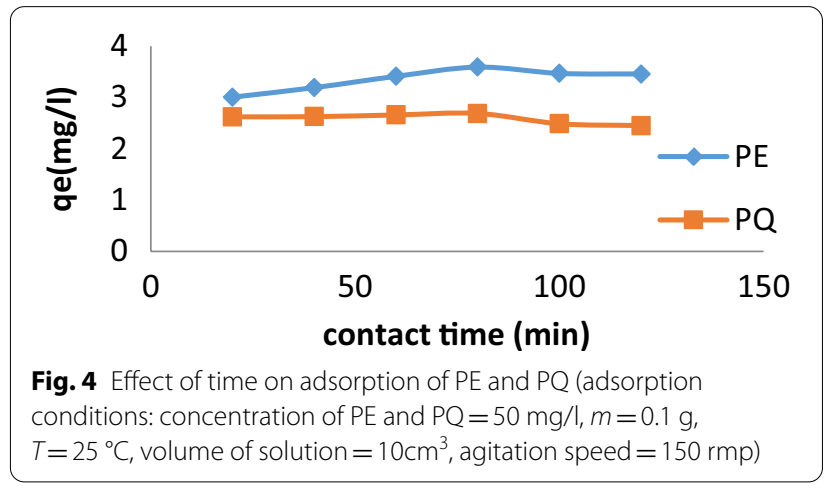

\section{Effect of $P E$ and $P Q$ adsorption duration}

Variation in the amount of PE and PQ molecules adsorbed with respect to duration is presented in Fig. 4. It was found that the adsorption rate of $\mathrm{PE}$ and $\mathrm{PQ}$ by ACBGNS was initially fast reaching equilibrium within $80 \mathrm{~min}$. PE and PQ molecules were firmly attached onto the ACBGNS resulting in a higher rate of adsorption. At 


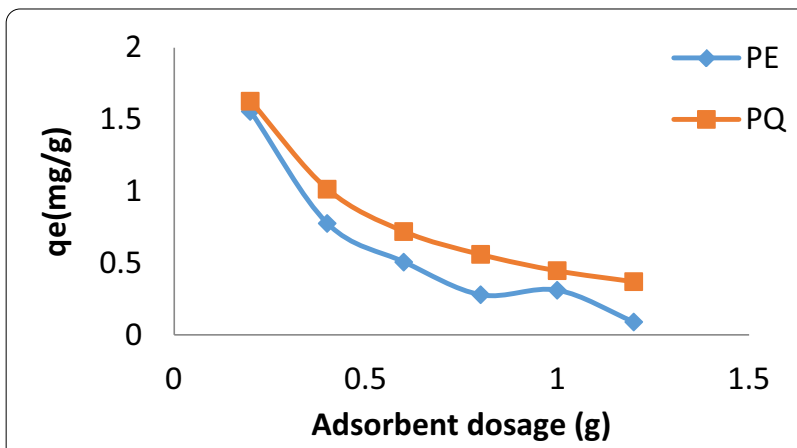

Fig. 5 Effect of adsorbent dosage on adsorption of ACBGNS onto $\mathrm{PE}$ and $\mathrm{PQ}$, (adsorption conditions: concentration of $\mathrm{PE}$ and $P Q=50 \mathrm{mg} / \mathrm{l}, t=2 \mathrm{~h}, T=25^{\circ} \mathrm{C}, \mathrm{m}=$ varied, volume of solution $=10 \mathrm{~cm}^{3}$, agitation speed $=150 \mathrm{rmp}$ )

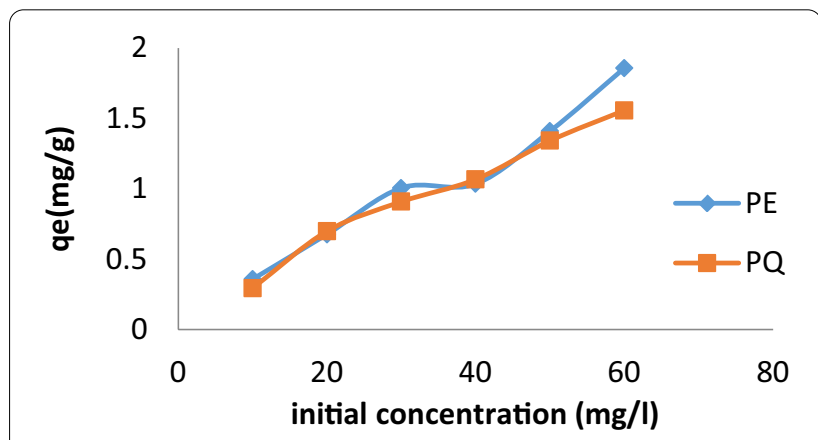

Fig. 6 Effect of initial concentration on adsorption of ACBGNS onto $\mathrm{PE}$ and $\mathrm{PQ}$ (adsorption conditions: concentration of PE and $\mathrm{PQ}=10-50 \mathrm{mg} / \mathrm{l}, m=0.2 \mathrm{~g}, t=2 \mathrm{~h}, T=25^{\circ} \mathrm{C}$, volume of solution $=10 \mathrm{~cm}^{3}$, agitation speed $=150 \mathrm{rmp}$ )

Table 1 Calculated Freundlich, Temkin and Langmuir Isotherm constants for the PQ and PE Adsorption onto ACBGNS

\begin{tabular}{llcc}
\hline Isotherm model & Parameter & Pendimethalin & $\begin{array}{c}\text { Paraquat } \\
\text { dichloride }\end{array}$ \\
\hline Langmuir & $Q_{\mathrm{o}}(\mathrm{mg} / \mathrm{g})$ & 52.63 & 142.86 \\
& $K_{\mathrm{L}}(\mathrm{L} / \mathrm{mg})$ & 0.056 & 0.0107 \\
& $R_{\mathrm{L}}$ & 0.186 & 0.379 \\
& $R^{2}$ & 0.976 & 0.993 \\
Freundlich & $1 / n$ & 1.486 & 1.190 \\
& $N$ & 0.673 & 0.840 \\
& $K_{\mathrm{f}}$ & 3.689 & 1.923 \\
Temkin & $R^{2}$ & 0.909 & 0.978 \\
& $A_{\mathrm{T}}(\mathrm{L} / \mathrm{mg})$ & 0.6358 & 0.376 \\
& $b_{T}$ & 223.81 & 201.76 \\
& $B$ & 11.07 & 12.28 \\
& $R^{2}$ & 0.780 & 0.971 \\
\hline
\end{tabular}

a later stage, the rate of PE and PQ removal was found to be constant. The available surfaces for binding the molecules became almost exhausted, and therefore, repulsive forces either between PE or PQ with the ACBGNS surface made the herbicide molecules difficult to occupy the vacant sites (Mondal and Kar 2018).

\section{Effect of adsorbent amount on adsorption of PE and $P Q$}

Figure 5 reveals the variation in equilibrium amount of PE and PQ adsorbed with adsorbent dosage (0.2-1.2 g). From the plots, the amount of PE and PQ adsorbed increased with an increase in the adsorbent amount used, while the amount adsorbed for a given amount of the adsorbent decreased considerably for both PE and PQ. This decrease observed for the herbicides in terms of adsorption per unit mass with respect to increasing adsorbent dosage could be attributed to possible overlapping of adsorption sites with an increase in adsorbent dosage. This is an indication that ACBGNS has a high adsorption capacity at low dosage.

\section{Effect of initial herbicide concentration on adsorption of PE and $\mathrm{PQ}$}

Figure 6 presents an increase in amount per gram of PE and PQ adsorbed as their initial concentration increases. Driving forces of molecules in solution are low at a lower concentration, therefore resulting in a lower adsorption rate, while when concentration increases, it is expected that the PE and PQ would have higher driving forces which enable them to easily occupy the active sites on the ACBGNS surface from the aqueous phase. This was reported by other researchers (Mondal and Kar 2018; Lee et al. 2019).

\section{Adsorption isotherm}

Three different isotherm models, Temkin, Freundlich and Langmuir, were used to treat the generated isotherm data with the intention of proposing adsorption process mechanism. The Langmuir's model has been used to describe the adsorption of monolayer which occurs on the outer surface of an adsorbent with infinite number of active adsorption sites.

$$
\frac{1}{q_{\mathrm{e}}}=\frac{1}{Q_{\mathrm{o}}}+\frac{1}{Q_{\mathrm{oKLC}}}
$$

$C_{\mathrm{e}}$ is the concentration of $\mathrm{PE}$ or $\mathrm{PQ}$ in $\mathrm{mg} / \mathrm{L}$ at equilibrium, $q_{\mathrm{e}}$, the amount of herbicide adsorbed per gram of the adsorbent at equilibrium $(\mathrm{mg} / \mathrm{g}), Q_{0}$ is maximum monolayer coverage capacity $(\mathrm{mg} / \mathrm{g}), K_{\mathrm{L}}$ is the isotherm constant $(\mathrm{L} / \mathrm{mg})$ for Langmuir. From the slope and intercept, the values of $\mathrm{q}_{\max }$ and $K_{\mathrm{L}}$ were evaluated through extrapolation of the Langmuir plot of $\frac{1}{q e}$ versus $\frac{1}{\mathrm{Ce}}$. The 
Table 2 Parameters for the kinetic adsorption of PE and PQ onto ACBGNS

\begin{tabular}{|c|c|c|c|c|}
\hline \multirow{2}{*}{$\begin{array}{l}\text { Kinetic models } \\
\text { Pseudo-first order }\end{array}$} & \multicolumn{4}{|c|}{ Numerical values } \\
\hline & $q_{\mathrm{eExp}}(\mathrm{mg} / \mathrm{g})$ & $q_{\mathrm{eCal}}(\mathrm{mg} / \mathrm{g})$ & $K_{1}\left(\min ^{-s}\right)$ & $R^{2}$ \\
\hline PE & 14.89 & 0.432 & 0.0023 & 0.098 \\
\hline$P Q$ & 13.01 & 1.236 & 0.021 & 0.781 \\
\hline Pseudo-second order & $q_{\mathrm{eExp}}(\mathrm{mg} / \mathrm{g})$ & $q_{\mathrm{eCal}}(\mathrm{mg} / \mathrm{g})$ & $K_{2}\left(\min ^{-s}\right)$ & $R^{2}$ \\
\hline$P E$ & 14.89 & 14.93 & 0.897 & 1 \\
\hline $\mathrm{PQ}$ & 13.01 & 13.16 & 0.058 & 0.999 \\
\hline Intra particle diffusion & & $K_{3}$ & $C$ & $R^{2}$ \\
\hline$P E$ & & 0.094 & 15.74 & 0.049 \\
\hline$P Q$ & & 0.172 & 11.28 & 0.614 \\
\hline
\end{tabular}

Table 3 Parameters for thethermodynamic adsorption of pendimethalin (PE) and paraquat dichloride (PQ) onto ACBGNS

\begin{tabular}{llllll}
\hline Adsorbate & $\boldsymbol{T}(\mathrm{K})$ & $\boldsymbol{K}_{\mathrm{c}}$ & $\boldsymbol{\Delta} \boldsymbol{G}(\mathrm{KJ} / \mathrm{mol})$ & $\boldsymbol{\Delta} \boldsymbol{H}(\mathrm{kJ} / \mathrm{mol})$ & $\boldsymbol{\Delta} \boldsymbol{S}(\mathrm{J} / \mathrm{mol} \mathrm{K})$ \\
\hline $\mathrm{PE}$ & 303 & 81.08 & -11.07 & 5.67 & 30.50 \\
& 313 & 55.07 & -10.43 & & \\
& 323 & 52.33 & -10.62 & & \\
& 333 & 29.96 & -9.413 & & 40.0 \\
$\mathrm{PQ}$ & 303 & 1.606 & -1.193 & 0.80 & \\
& 313 & 1.495 & -1.046 & & \\
& 323 & 1.490 & -1.071 & &
\end{tabular}

Table 4 PE and PQ quantum chemical parameters

\begin{tabular}{lll}
\hline Properties & Pendimethalin & Paraquat dichloride \\
\hline HOMO (at orbital number) & 75 & 43 \\
LUMO (at orbital number) & 76 & 44 \\
$E_{\text {HOMO }}(\mathrm{eV})$ & -5.306 & -3.085 \\
$E_{\text {LUMO }}(\mathrm{eV})$ & -3.280 & -0.963 \\
$\triangle E(\mathrm{eV})$ & 2.026 & 2.122 \\
Dipole moment (Debye) & 2.730 & 2.190 \\
Binding energy (kal/mol) & -4695.753 & -2999.686 \\
lonization potential (I) (eV) & 5.306 & 3.085 \\
Electron affinity (A) (eV) & 3.280 & 0.963 \\
Global hardness $(\eta)$ & 1.013 & 1.061 \\
Global softness ( $)$ & 0.987 & 0.943 \\
Absolute electronegativity $(X)$ & 4.293 & 2.024 \\
Polarizability $\left(\nearrow^{*}\right)\left(\mathrm{A}^{3}\right)$ & 78.439 & 27.597 \\
Surface area $(\mathrm{SA})\left(\mathrm{A}^{2}\right)$ & 307.88 & 302.58 \\
Surface volume $(\mathrm{SV})\left(\mathrm{A}^{3}\right)$ & 281.65 & 258.86 \\
\hline
\end{tabular}

Langmuir adsorption parameters obtained from the plots (figures not shown) are reported in Table 1. From the presented results, the value of $Q_{o}$ is higher for PQ than for PE. $Q_{0}$ is generally equivalent to the coverage of maximum adsorption capacity, indicating an increasing $Q_{0}$ value toward better adsorption. Hence, higher $Q_{0}$ obtained for PQ confirms that ACBGNS adsorbed PQ better than PE. Freundlich isotherm model's empirical Eq. (11) can be used to describe the adsorption over heterogeneous surface of herbicides (Guo and Wang 2019).

$$
\log Q_{e}=\log k f+\frac{1}{n} \log C_{e}
$$

$K_{\mathrm{F}}$ in the Freundlich's equation describes adsorption capacity constant. The adsorption intensity's empirical parameter can be defined by $1 / n$. From this study, it is clear that the capacity adsorption can depend on major factors including the nature of adsorbent and the type of herbicide used. The calculated values of $R_{\mathrm{L}}$ for the two herbicides are given in Table 1 which shows PE and PQ adsorption onto ACBNGS surface is favorable. As tabulated in table, values of $\mathrm{n}$ ranged between 0 and 1 qualifying a favorable adsorption.

When the surface coverage is related to the adsorption free energy during the interaction of the herbicides with the adsorbent surface, we consider the isotherm described by the Temkin model. In addition, the heat of adsorption associated with the herbicide molecules on the layer is found to decrease proportionately because of adsorbent-adsorbate interaction. This type of adsorbate-adsorbent interaction is associated with uniformly associated binding energies, to reach a maximum value (Al-Saad et al. 2019). This statement is as presented by the following relation in Eq. (12):

$$
q_{e}=\frac{\mathrm{RT}}{b_{T}} \ln A_{T}+\left(\frac{\mathrm{RT}}{b_{T}}\right) \ln C_{e}
$$

The Temkin constant $B=\mathrm{RT} / b$ is related to the heat of adsorption, the molar gas constant is $R(\mathrm{~J} / \mathrm{mol} K)$, the temperature is $\mathrm{T}(\mathrm{K})$, the adsorption energy variation is 
Table 5 Calculated Fukui indices for the studied inhibitor molecules

\begin{tabular}{|c|c|c|c|c|c|c|c|c|}
\hline \multirow[t]{3}{*}{ Molecule } & \multicolumn{4}{|c|}{ Electrophilic $\left(\mathbf{F}^{-}\right)$} & \multicolumn{4}{|c|}{ Nucleophilic $\left(F^{+}\right)$} \\
\hline & \multicolumn{2}{|c|}{ Mulliken } & \multicolumn{2}{|c|}{ Hirsfeld } & \multicolumn{2}{|c|}{ Mulliken } & \multicolumn{2}{|c|}{ Hirsfeld } \\
\hline & Atom & Value & Atom & Value & Atom & Value & Atom & Value \\
\hline \multirow[t]{2}{*}{ PE } & $N(1)$ & 0.105 & $N(1)$ & 0.096 & $\mathrm{O}(17)$ & 0.124 & $\mathrm{O}(17)$ & 0.100 \\
\hline & $\mathrm{O}(15)$ & 0.079 & $\mathrm{O}(15)$ & 0.077 & $\mathrm{O}(18)$ & 0.123 & $\mathrm{O}(18)$ & 0.114 \\
\hline$P Q$ & $C(5)$ & 0.079 & $H(13)$ & 0.075 & $C(11)$ & 0.094 & $C(11)$ & 0.095 \\
\hline
\end{tabular}

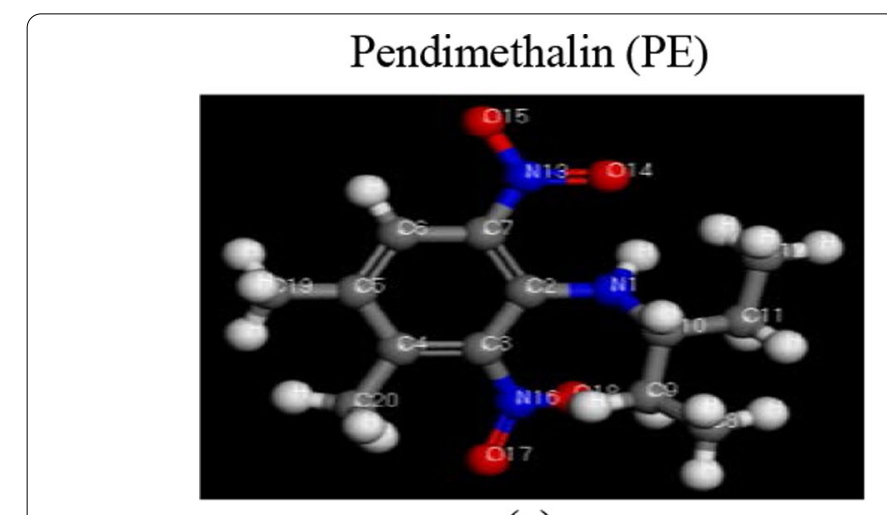

(a)

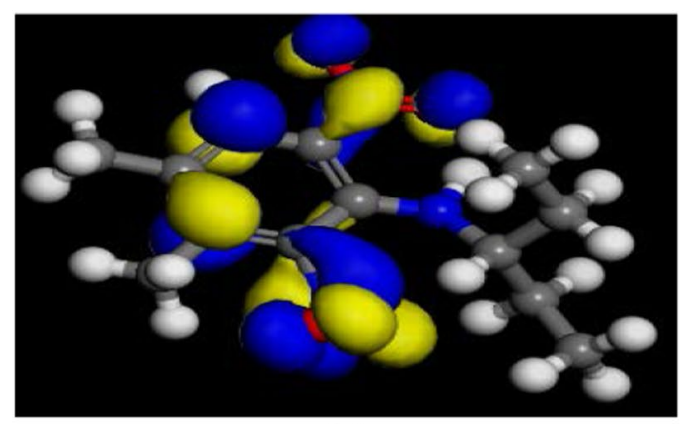

(b)

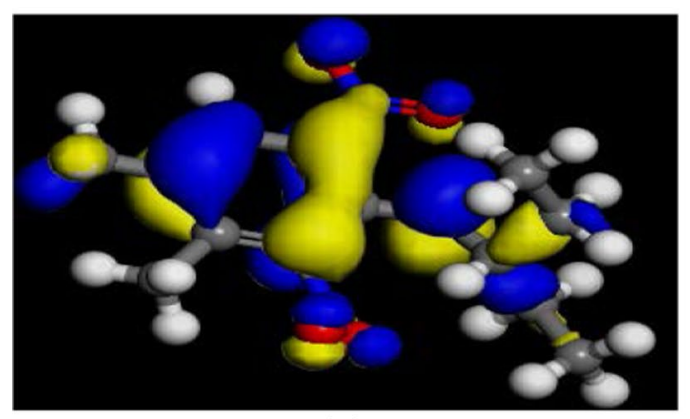

(c)

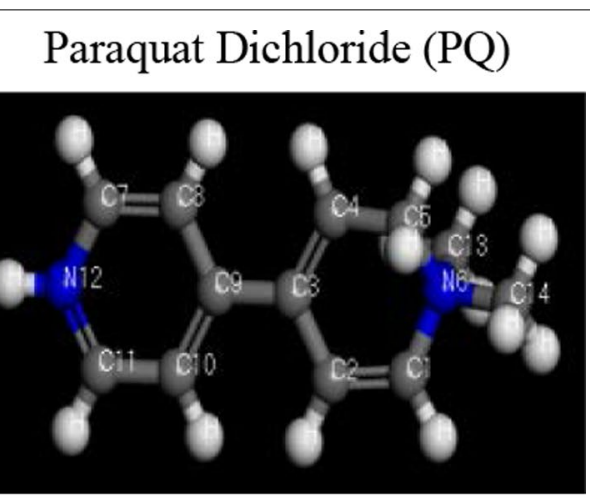

(a)

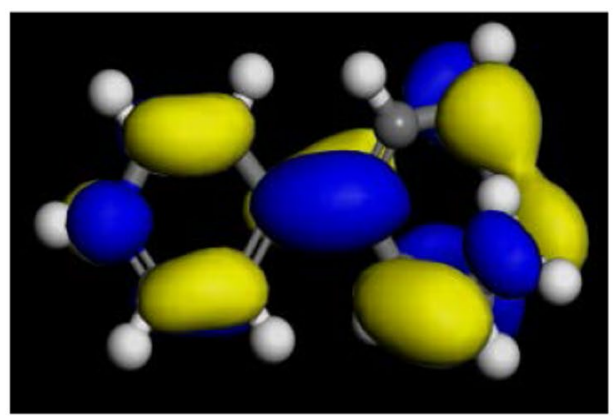

(b)

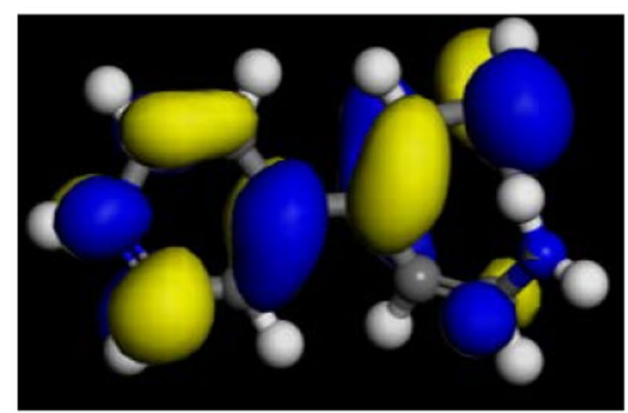

(c)

Fig. 7 (a) Optimized geometry (b) HOMO (c) LUMO of PE and PQ molecules [functional: B3LYP/PWC, Quality fine]

$b(\mathrm{~J} / \mathrm{mol})$ and the binding constant at equilibrium is $b_{\mathrm{T}}$ $(\mathrm{L} / \mathrm{mg})$ which is equivalent to binding energy at maximum value (Araujo et al. 2018). Table 1 contains the summary of all parameters calculated for Temkin isotherm. From Table 1 , both $b_{\mathrm{T}}$ and $B$ values for PE and PQ were reported as 223.81 and 11.07 , respectively. The 
regression equation and $\mathrm{R}^{2}$ value observed for this model favorably described the adsorption process of the herbicides onto ACBGNS, across the experimental variables applied. When the values of the correlation coefficient, $R^{2}$, were compared for the three tested isotherms, relatively, the Langmuir model fitted better among others for the adsorption data of herbicide onto ACBGNS.

\section{Kinetic study}

The kinetic studies of systems involved in adsorption describe how fast the adsorbate uptake onto the adsorbent is which controls the amount of equilibration time. The adsorption kinetic curves of the PE and PQ molecules on ACBGNS were obtained by subjecting the experimental data obtained to three models of kinetics comprising pseudo-first and second-order and intraparticle diffusion.

\section{(a) Kinetic model of the pseudo-first-order}

Equation (13) can be used to define the model (Benkaddour et al. 2018).

$$
\log \left(q_{e}-q_{t}\right)=\log \left(q_{e}\right)-\frac{K_{1}}{2.303} t
$$

$k_{1}$ is the rate constant and $q_{\mathrm{e}}$ is the amounts $(\mathrm{mg} / \mathrm{g})$ of PQ while $q_{t}$ is that of PE adsorbed at equilibrium and time $t$, respectively. $\log \left(q_{\mathrm{e}}-q_{t}\right)$ was plotted against $t$, and values associated with $k_{1}$ were evaluated from the graph's slope. $R^{2}$ values, calculated and experimental $q_{\mathrm{e}}$ values obtained for PE and PQ adsorption onto ACBGNS are presented in Table 2. $R^{2}$ was observed to be very low coupled with a reasonable difference established between the adsorption capacity $\left(q_{e}\right)$ values for experimental and calculated, showing failure in experimental data interpretation.

\section{(b) Kinetic model of the pseudo-second-order}

This type of second order has been widely to predict kinetics of adsorption processes and the expression is as in Eq. (14) (Hameed et al. 2009).

$$
\frac{t}{q_{t}}=\frac{1}{K_{2 q_{e}^{2}}}+\frac{1}{q_{e}}(t)
$$

Adsorption rate constant is given by $k_{2}(\mathrm{~g} / \mathrm{mg} \mathrm{min})$, while $t / q_{t}$ values were plotted against $t$ (figure not shown). According to the kinetic model of the pseudo-second order, parameters of adsorption of herbicides onto ACBGNS are given in Table 2. From the results, parameters obtained were found to fit the equation with the $R^{2}$ values close to unity. There was good correlation between the calculated and experimental values. The use of this model in adsorption process describing the adsorption of $\mathrm{PE}$ and PQ herbicides onto ACBGNS was proved based on such comparison.

\section{(iii) Intraparticle diffusion model}

Weber-Moris Eq. (15) predicts the possibility of the sole mechanism through the intra particle diffusion model (Raul et al. 2011).

$$
q_{e}=C+K_{\mathrm{int}}^{t 1 / 2}
$$

The constant $k_{\text {int }}(\mathrm{mg} / \mathrm{g}$ min 0.5$)$ describes rate of diffusion, while the boundary layer thickness is defined by C. If the rate-limiting step is only through intra particle diffusion, then a linear plot would be obtained when $q_{t}$ versus $t 1 / 2$ is extrapolated to the origin. If not, there is involvement of other mechanism. The values of the constant $C$ from Table 2 were found to 15.74 and 11.28 for $\mathrm{PE}$ and $\mathrm{PQ}$, respectively. It can be concluded that $\mathrm{PQ}$ and $\mathrm{PE}$ adsorption by the ACBGNS cannot be predicted by this model.

\section{Thermodynamic adsorption study}

Notably parameters obtained from thermodynamic evaluations give vital information about the adsorption nature with respect to feasibility and spontaneity of the process. Temperature effects associated with PQ and PE adsorption onto ACBGNS were studied by temperature variation from 303 to $333 \mathrm{~K}$ while keeping all other parameters $(\mathrm{pH}=6$ and 8 , respectively, for $\mathrm{PE}$ and PE, adsorbent dosage $0.2 \mathrm{~g}$, initial PQ concentration $=60 \mathrm{mg} / \mathrm{l}, t=80 \mathrm{~min}$ ) at optimized values. The thermodynamic constants for adsorption which can be used to describe the spontaneity and feasibility of an adsorption process are described entropy $(\Delta S)$, free energy $(\Delta G)$ and enthalpy $(\Delta H)$ changes. Equations (16) and (17) describe them thus:

$$
\begin{aligned}
& \Delta G=-\mathrm{RT} \ln K_{\mathrm{c}} \\
& \ln k_{\mathrm{c}}=-(\Delta H / \mathrm{RT})+(\Delta S / R)=-\Delta G / \mathrm{RT}
\end{aligned}
$$

the temperature being $T(K)$, the gas constant, $R$, $8.314 \mathrm{~J} / \mathrm{mol} \mathrm{K}$ and $k_{\mathrm{c}}$ the constant of equilibrium which can be obtained from the relation in Eq. (18) (Calvete et al. 2010).

$$
k_{\mathrm{c}}=C_{\mathrm{a}} / C_{\mathrm{e}}
$$

where $C_{\mathrm{a}}$ is the adsorbed herbicide in $\mathrm{mg} / \mathrm{L}$ and the equilibrium herbicide concentration is $C_{\mathrm{e}}(\mathrm{mg} / \mathrm{L})$. The slope from the van't Hoff's plot and intercept and the values of $\Delta S$ and $\Delta H$ were evaluated, and Table 3 contains all the 
calculated values. $\Delta \mathrm{H}$ values which were found to be positive show that an endothermic process is involved fort the adsorption of the herbicides onto ACBGNS. The positive value of $\triangle S$ indicates high randomness at $\mathrm{PQ}$ and $\mathrm{PE}$ molecules adsorption interphase onto ACBGNS (Gunay et al. 2007). Physical adsorption has values in the range of $2.1-20.9 \mathrm{~kJ} / \mathrm{mol}$, which describes the type of adsorption for both herbicides involved in this research, while higher range of $80-200 \mathrm{~kJ} / \mathrm{mol}$ can be used to qualify chemisorption mechanism. $\Delta G$ values which are negative show the adsorption is thermodynamically feasible and spontaneous (Mustapha et al. 2019).

\section{Computational study}

Quantum chemical parameters of PE and PQ molecules calculated are presented in Table 4 which shows smaller energy gap $(\Delta E)$ of $\mathrm{PE}$ as compared to $\mathrm{PQ}$. This gap in energy $(\Delta E)$ can be used to describe softness and hardness of a molecule. Lower $\Delta \mathrm{E}$ (and vice versa) describes soft molecules with tendency of better adsorption compared to hard molecules. Therefore, lower values of $\Delta E$ correlate well with the ease of adsorption of molecules onto an adsorbent. Eigen values of $E_{\mathrm{HOMO}}$ and $E_{\mathrm{LUMO}}$ as presented in Table 4 describe that PQ herbicide adsorption is higher than that of PE which may be due to the presence of chloride ion in solution and lone pairs of nitrogen increase its activity which is in good agreement with that earlier reported here experimentally. Relationship between adsorption and dipole moment is yet to be fully established in literature with most adsorption processes reported to favor lower $\mu$ as shown in Table 4. The $\mu$ for PQ is lower than that of PE and therefore better adsorbed. The adsorption ability of a chemical compound can be controlled by its binding energy $\left(E_{\mathrm{B}}\right)$, surface volume (SV), surface area (SA). The higher the values of SV, $\mathrm{SA}, E_{\mathrm{B}}$ obtained, then the process of protonation, hydration and subsequent adsorption on a surface for a given molecule becomes more difficult. Therefore, lower values of these parameters associated with PQ herbicide show that it is better protonated, hydrated and adsorbed on ACBGNS than PE herbicide.

In the presence of charge atmosphere, polarizability can be defined as a measure of the behavior of molecular species. Tendency of the ease of a molecule to be adsorbed is related to better response. This explains why PQ herbicide is better adsorbed on ACBGNS than PE herbicide. Better adsorption of PQ is also favored by their SV and SA values which are low. It is established that molecules compete with difficulty to fit into the adsorption matrix of the adsorbent when the values of surface area and volume of the adsorbate are large.

An index, the function of Fukui can be used to assess the local reactivity (hence adsorption) of a molecule on the basis of the constituent atoms which are electronic in nature (Alokdut et al. 2017). Based on electrophilic and nucleophilic nature of the chemical reactivity of a molecule, Fukui indices provide useful information about the reactive centers (Mohan and Joseph 2018; Zohdy et al. 2021). Threshold values of $f_{k}^{+}$andf $_{\mathrm{k}}^{-}$control nucleophilic and electrophilic centers of in a given molecule. PE and PQ herbicide's Fukui functions are shown in Table 5. $\mathrm{F}^{-}$ for PE and PQ molecule have their highest Mulliken and Hirshfeld charges on $\mathrm{N}(1)$ and $\mathrm{H}(13), \mathrm{C}(5)$ while for the nucleophilic $\left(\mathrm{F}^{+}\right)$, PE herbicide on $\mathrm{O}(17), \mathrm{O}(18)$ and $\mathrm{PQ}$ herbicide are on the aromatic ring $\mathrm{N}(5)$ shown in Table 5. Therefore, the adsorption of PE on ACBGNS occurs through the nitrogen atom while that of PQ occurs via the aromatic ring of the molecule. Optimized geometry, Frontier orbital diagrams of PE and PQ herbicides are reported in Fig. 7. Within the diagrams, red loop shows positive sites while negative charges are displayed in blue loops on the molecules.

\section{Conclusions}

The present study has demonstrated that activated Bambara groundnut shell can be used as a natural, promising, economic and environmentally friendly adsorbent for PE and PQ removal from aqueous solutions. FTIR, SEM, moisture content, pore volume and bulky density were used to analyze for the functional groups and surface area that are responsible for the herbicide ion removal from aqueous solutions. The batch adsorption method is dependent on the contact time, dosage, solution $\mathrm{pH}$ and initial herbicide ion concentrations. The experimental data in the adsorption process indicated good correlations with the pseudo-second-order kinetic model and Langmuir isotherm. The thermodynamic study showed that the process is highly endothermic in nature, with positive value of $\Delta H$ and change in $\Delta S$. Based on this study, the readily available Bambara groundnut shell which is cheaply available to the environment could be used as a natural adsorbent, due to its high removal efficiencies of the herbicide ion involved in this study. Studied computational parameters and that of the experimental supported each other with high degree of similarities.

\section{Abbreviations}

PE: Pendimethalin; PQ: Paraquat dichloride; ACBGNS: Activated Bambara groundnut shells; DFT: Density functional theory; $\triangle G$ : Change in Gibb's energy; $\Delta H$ : Change in enthalpy; $\Delta S$ : Change in entropy.

\section{Acknowledgements}

None. 


\section{Authors' contributions}

AMA did the conception and designed of the work, TAN performed the experiment and interpreted the data and was a major contributor in writing the manuscript, and HFC substantively revised the manuscript. All authors read and approved the final manuscript.

\section{Funding}

Funding was not received

Availability of data and materials

It has been reported and cited in the methodology section of the manuscript.

\section{Declarations}

Ethics approval and consent to participate

Not applicable.

\section{Consent for publication}

Not applicable.

\section{Competing interests}

The authors declare that they have no competing of interests.

\section{Author details}

${ }^{1}$ Department of Pure and Industrial Chemistry, Bayero University, Kano, Kano, Nigeria. ${ }^{2}$ Department of Chemistry, Federal University of Agriculture, Makurdi, Makurdi, Nigeria.

Received: 13 April 2021 Accepted: 25 October 2021

Published online: 10 November 2021

\section{References}

Abate GY, Alene AN, Habte AT, Getahun DM (2020) Adsorptive removal of malachite green dye from aqueous solution onto activated carbon of catha edulis stem as a low cost bio-adsorbent. Environ Syst Res 9:29

Abbas AF, Ahmed MJ (2016) Mesoporous activated carbon from date stones (Phoenix dactylifera L.) by one-step microwave assisted $\mathrm{K}_{2} \mathrm{CO}_{3}$ pyrolysis. Water Process Eng 9:201-207

Abd El Salam HM, Zaki T (2019) A novel microwave synthesis of manganese based MOF for adsorptive of $\mathrm{Cd}(\mathrm{II}), \mathrm{Pb}(\mathrm{II})$ and $\mathrm{Hg}(\mathrm{II})$ ions from aqua medium. Egypt J Chem 62:1237-1251

Abdelhamid AE, El-Sayed AA, Khalil AM (2020) Polysulfone nano functionalized grapheme oxide for dye removal from wastewater. J Polym Eng 40:833-841. https://doi.org/10.1515/polyeng-2020-0141

Ademola MA, Abimbola FA, Sylvester Cl, Jeremiah OJ (2019) Acute toxicity of paraquat dichloride on fingerlings of Oreochromis niloticus. Int J Res Stud Biosci 7(1):29-36. https://doi.org/10.20431/2349-0365.0701005

Ahmed MK, Sayed HK (2020) Hybrid membranes based on clay-polymer for removing methylene blue from water. Acta Chim Slov 67:96-104. https:// doi.org/10.17344/acsi.2019.5227

Ahmed EA, Ahmed AE, Ahmed MK (2020) Polysulfone nano filtration membranes enriched with functionalized graphene oxide for dye removal from wastewater. J Polym Eng 40:833-841

Akinola LK, Ali I, Mohammed M (2019) Adsorption of methylene blue on adsorbents derived from delonix regia seed pods and vigna subterranea fruit hulls: a kinetic study. Sci World J 14:1

Ali I, Athman ZA, Al-Warthan A (2016) Sorption, kinetics and thermodynamics studies of atrazine herbicide removal from water using iron nano-composite material. Int J Environ Sci Technol 13:733-742. https://doi.org/10. 1007/s13762-015-0919-6

Alibakhshi E, Ramezanzadeh M, Bahlakeh G, Ramezanzadeh B, Mahdavian M, Motamedi M (2018) Glycyrrhiza glabra leaves extract as a green corrosion inhibitor for mild steel in $1 \mathrm{M}$ hydrochloric acid solution: experimental, molecular dynamics, monte carlo and quantum mechanics study. J Mol Liq 255:185-198

Alokdut D, Sourav KS, Utpal A, Priyabrata B, Dipankar S (2017) Effect of substitution on corrosion inhibition properties of 2- (substituted phenyl) benzimidazole derivatives on mild steel in $1 \mathrm{M} \mathrm{HCl}$ solution: a combined experimental and theoretical approach. Corros Sci 123:256-266

Al-Saad K, El-Azazy M, Issa AA, Al-Yafie A, El-Shafie AS, Al-Sulaiti M, Shomar B (2019) Recycling of date pits into a green adsorbent for removal of heavy metals: a fractional factorial design-based approach. Front Chem 7(552):1-16

Alzhan B, Dmitriy B, Seitkhan A, Talgat N, Vassilis I (2020) Removal of Cd2+ from water by use of super-macroporous cryogels and comparison to commercial adsorbents. Polymers 12:2405. https://doi.org/10.3390/ polym12102405

Araújo CST, Almeida ILS, Rezende HC, Marcionilio SMLO, Léon JJL, de Matos TN (2018) Elucidation of mechanism involved in adsorption of Pb(II) onto Lobeira fruit (Solanum lycocarpum) using Langmuir, Freundlich and Temkin isotherms. Micro Chem J 137:348-354

Ayuba AM, Nyijime TA (2020) Kinetic and equilibrium studies of paraquat dichloride adsorption on raw Bambara groundnut (vigna subteranean) shells. Appl J Envir Eng Sci 6:1-13

Ayuba AM, Nyijime TA (2021) Removal of pendimethalin herbicide from aqueous solution using untreated bambara groundnut hulls as a low-cost adsorbent. J Mater Environ Sci 12:15-26

Becke AD (1993) Density-functional thermochemistry. III. The role of exact exchange. J Chem Phys 8:5648-5653

Bedin KC, Martins AC, Cazetta AL (2015) KOH-activated carbon prepared from sucrose spherical carbon: adsorption equilibrium, kinetic and thermodynamic studies for methylene blue removal. Chem Eng J 286:476-484

Bello OS, Adegoke KA, Akinyunni OO (2017) Preparation and characterization of a novel adsorbent from Moringa oleifera leaf. Appl Water Sci 7:1295-1305

Benkaddour S, Slimani R, Hiyane H, El Ouahabi I, Hachoumi I, El Antri S, Lazar S (2018) Removal of reactive yellow 145 by adsorption onto treated watermelon seeds: kinetic and isotherm studies. Sustain Chem Pharm 10:16-21

Calvete T, Lima EC, Cardoso NF, Dias SLP, Ribeiro ES (2010) Removal of brilliant green dye from aqueous solutions using homemade activated carbons. Clean: Soil, Air, Water 38:521-532

El-Azazy M, El-Shafie AS, Al-Meer S, Al-Saad KA (2021) Ecostructured adsorptive removal of tigecycline from wastewater: date pits' biochar versus the magnetic biochar. Nanomaterials 11(1):30

El-Shamy AM, Abdelfattah I, Elshafey OI, Shehata MF (2018) Potential removal of organic loads from petroleum wastewater and its effect on the corrosion behavior of municipal networks. J Environ Manag 219:325-331

Emreguland KC, Hayvali M (2006) Studies on the effect of a newly synthesized Schiff base compound from phenazone and vanillin on the corrosion of steel in $2 \mathrm{M} \mathrm{HCl}$. Corros Sci 48:797-812

Fito J, Said H, Feleke S, Worku A (2019) Fluoride removal from aqueous solution onto activated carbon of Catha edulis through the adsorption treatment technology. Environ Syst Res 8:25

Fouodjouo M, Fotouo-Nkaffo H, Laminsi S, Cassini FA, de Brito-Benetoli LO, Debacher NA (2017) Adsorption of copper(II) onto cameroonian clay modified by non-thermal plasma: characterization, chemical equilibrium and thermodynamic studies. Appl Clay Sci 42:136-144. https://doi.org/ 10.1016/j.clay.2016.09.028

Growcock FB (1989) Inhibition of steel corrosion in $\mathrm{HCl}$ by derivatives of cinnamaldehyde. Corros Sci 45:1003-1007

Gunay A, Arslankaya E, Tosun I (2007) Lead removal from aqueous solution by natural and pretreated clinoptilolite: adsorption equilibrium and kinetics. J Hazard Mater 146:362-371

Guo X, Wang J (2019) Comparison of linearization methods for modeling the Langmuir adsorption isotherm. J Mol Liq 296:111850

Hameed BH, Salman JM, Ahmad AL (2009) Adsorption isotherm and kinetic modeling of 2,4-D pesticide on activated carbon derived from date stones. J Hazard Mater 163:121-126

Hinchliffe A (1994) Modelling molecular structures. Wiley, New York

Hinchliffe A (1999) Chemical modelling from atoms to liquids. Wiley, New York

Jawad AH, Abdulhameed AS (2020) Mesoporous Iraqi red kaolin clay as an efficient adsorbent for methylene blue dye: adsorption kinetic, isotherm and mechanism study. Surf Interface 18:100422

Jawad AH, Ngoh YS, Radzun KA (2018) Utilization of watermelon (Citrullus lanatus) rinds as a natural low-cost biosorbent for adsorption of methylene blue: kinetic, equilibrium and thermodynamic studies thermodynamic studies. J Taibah Univ Sci 12:371-381 
Karelson M, Lobanov V (1996) Quantum chemical descriptors in QSAR/QSPR studies. Chem Rev 96:1027-1043

Khaled KF, Babic-Samardzija K, Hackerman N (2005) Theoretical study of the structural effects of polymethylene amines on corrosion inhibition of iron in acid solutions. Electrochim Acta 50:2515-2520

Khalil AM, Kenawy SH (2020) Hybrid membranes based on clay polymer for removing methylene blue from water. Acta Chim Slov 67:96-104. https:// doi.org/10.17344/acsi.2019.5227

Khan RH (2020) Chromium removal from tannery industry waste water by fungus. IOSR J Environ Sci Toxicol Food Technol 14:35-54

Koopmans T (1993) Ordering of wave functions and eigen energies to the individual electrons of an atom. Physica 1:104-113

Kraka E, Cremer D (2000) Computer design of anticancer drugs. J Am Chem Soc 122:8245-8264

Lashkari M, Arshadi MR (2004) DFT studies of pyridine corrosion inhibitors in electrical double layer: solvent, substrate, and electric field effects. Chem J Chem Phys 299:131-137

Lee C, Yang W, Parr RG (1988) Development of the Colle-Salvetti correlationenergy formula into a functional of the electron density. Phys Rev B 37:785-793

Lee S-L, Park J-H, Kim S-H, Kang S-W, Cho J-S, Jeon J-R, Lee Y-B, Seo D-C (2019) Sorption behavior of malachite green onto pristine lignin to evaluate the possibility as a dye adsorbent by lignin. Appl Biol Chem 62:37

Liliana SP, Roger MN, Emanuel HN, Manuel FB, Jorge M, German GV (2020) Selection of the activated carbon type for the treatment of landfill leachate by fenton-adsorption process. Molecules 25:3023. https://doi.org/ 10.3390/molecules25133023

Mohammad M, Ruby A, Jeenat A (2017) Nontoxic biodegradable cationic gemini surfactants as novel corrosion inhibitor for mild steel in hydrochloric acid medium and synergistic effect of sodium salicylate: experimental and theoretical approach. Mater Chem Phys 191:151-167

Mohan R, Joseph A (2018) Corrosion protection of mild steel in hydrochloric acid up to $313 \mathrm{~K}$ using propyl benzimidazole: electro analytical, adsorption and quantum chemical studies. Egypt J Petrol 27:11-20

Mondal NK, Kar S (2018) Potentiality of banana peel for removal of congo red dye from aqueous solution: isotherm, kinetics and thermodynamics studies. Appl Water Sci 8:157

Mustapha S, Shuaib DT, Ndamitso MM, Etsuyankpa MB, Sumaila A, Mohammed UM, Nasirudeen MB (2019) Adsorption isotherm, kinetic and thermodynamic studies for the removal of $\mathrm{Pb}(\mathrm{II}), \mathrm{Cd}(\mathrm{II}), \mathrm{Zn}(\mathrm{II})$ and $\mathrm{Cu}(\mathrm{II})$ ions from aqueoussolutions using Albizia lebbeck pods. Appl Water Sci 9:142

Neera S (2009) Adsorption of herbicides on coal fly ash from aqueous solutions. J Hazard Mater 168:233-237. https://doi.org/10.1016/j.jhazmat. 2009.02 .016
Parr RG, Yang W (1984) Electon density, Kohn-sham frontier orbitals and Fukui functions. J Am Chem Soc 106:4049-4050

Parr RG, Szentpaly L, Liu S (1999) Electrophilicity index. J Am Chem Soc 121:1922-1924

Pearson RG (1963) Hard and soft acids and bases. J Am Chem Soc 22:3533-3539

Raul OP, Roberto LR, Jovita MB, Rosa GCM (2011) Adsorption rate of phenol from aqueous solution onto organobentonite: surface diffusion and kinetic models. J Colloid Interface Sci 364:195

Salman JM, Hameed BH (2010) Removal of insecticide carbofuran from aqueous solutions by banana stalks activated carbon. J Hazard Mater $176: 814-819$

Salman JM, Njokua VO, Hameeda BH (2011) Adsorption of pesticides from aqueous solution onto banana stalk activated carbon. Chem Eng J 174:41-48. https://doi.org/10.1016/j.cej.2011.08.026

Tao Z, Zhang S, Liand W, Hou B (2010) Adsorption and corrosion inhibition behavior of mild steel by one derivative of benzoic-triazole in acidic solution. Ind Eng Chem Res 49:2593-2599

Verma C, Lgaz H, Verma DK, Ebenso EE, Bahadur I, Quraishi MA (2018) Molecular dynamics and monte carlo simulations as powerful tools for study of interfacial adsorption behavior of corrosion inhibitors in aqueous phase: a review. J Mol Liq 260:99-120

Wang D, Li SY, Ying M, Wang H, Xiao H, Chen Z (1999) Theoretical and experimental studies of structure and inhibition efficiency of imidazoline derivatives. Corros Sci 41:1911-1999

Wei B, Cheng X, Wang G, Li H, Song X, Dai L (2019) Graphene oxide adsorption enhanced by Attapulgite to remove $\mathrm{Pb}(\mathrm{II})$ from aqueous solution. Appl Sci 9:1390

Yanyan L, Kurniawan T, Albadarin A, Walker G (2018) Enhanced removal of acetaminophen from synthetic wastewater using multi-walled carbon nanotubes (MWCNTs) chemically modified with $\mathrm{NaOH}, \mathrm{HNO} 3 / \mathrm{H} 2 \mathrm{SO} 4$, ozone, and/or chitosan. J Mol Liq 251:369-377

Zohdy KM, El-Sherif RM, Ramkumar S, El-Shamy AM (2021) Quantum and electrochemical studies of the hydrogen evolution findings in corrosion reactions of mild steel in acidic medium. Upstream Oil Gas Technol 6:100025

\section{Publisher's Note}

Springer Nature remains neutral with regard to jurisdictional claims in published maps and institutional affiliations.

\section{Submit your manuscript to a SpringerOpen ${ }^{\circ}$ journal and benefit from:}

- Convenient online submission

- Rigorous peer review

- Open access: articles freely available online

- High visibility within the field

Retaining the copyright to your article

Submit your next manuscript at $\boldsymbol{\nabla}$ springeropen.com 